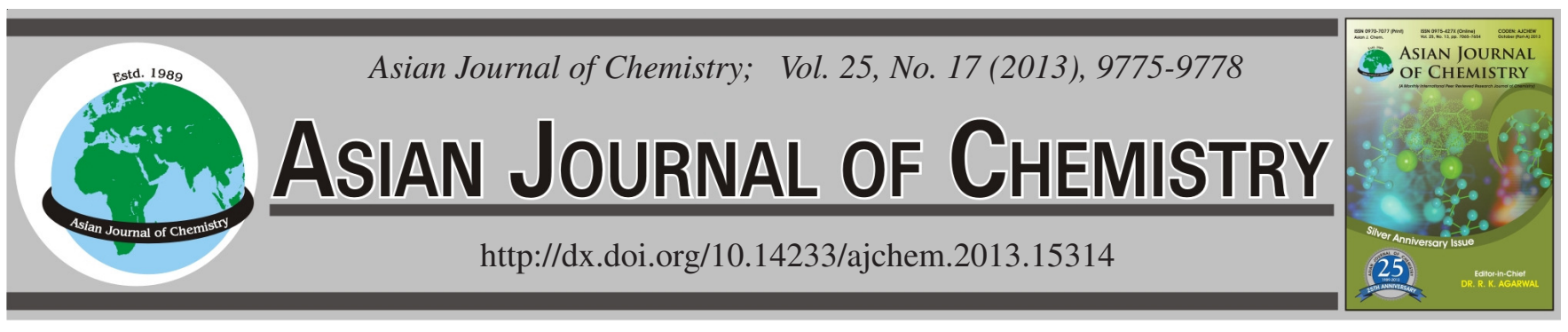

\title{
A Stability Indicating UPLC Method for the Estimation of Related Substances, Assay and Dissolution of Rufinamide
}

\author{
M. Geetha ${ }^{1, *}$, Shakil Sait ${ }^{1}$ and Palavai SRipal Reddy ${ }^{2}$
}

${ }^{1}$ Dr. Reddy's Laboratories Ltd. IPDO, Bachupally, Hyderabad-500 072, India

${ }^{2}$ Department of Chemistry, Jawaharlal Nehru Technological University, Kukuatpally, Hyderabad-500 0072, India

*Corresponding author: Fax: +91 40 44346313; E-mail: geetharm@ drreddys.com

(Received: 11 February 2013;

Accepted: 23 October 2013)

AJC-14273

\begin{abstract}
The objective of the present research work is to develop an isocratic, reversed-phase liquid chromatographic (RP-UPLC) method for the determination of rufinamide in pharmaceutical dosage forms for assay, dissolution and its related impurities. The chromatographic separation was achieved on a Waters ACQUITY TM UPLC BEH C ${ }_{18}$ column $(150 \mathrm{~mm} \times 2.1 \mathrm{~mm}, 1.7 \mu \mathrm{m})$. The isocratic LC method employs mixture of buffer, methanol and tetrahydrofuran in the ratio of $(80: 15: 5 \mathrm{v} / \mathrm{v})$ solutions as mobile phase. The buffer solution contains $0.02 \mathrm{M}$ potassium dihydrogen orthophosphate, $\mathrm{pH}$ adjusted to 4.5 with diluted orthophosphoric acid solution. The flow rate was $0.3 \mathrm{~mL} / \mathrm{min}$ and the detection wavelength was $210 \mathrm{~nm}$. In the developed UPLC method, the resolution between rufinamide and its potential impurities, namely impurity-1, impurity-2 and impurity-3 was found to be greater than 2 . The pharmaceutical dosage form was subjected to stress conditions of hydrolysis. Considerable degradation was found to occur in acidic medium and mild degradation observed in base hydrolysis stress conditions. Degradation product formed during acidic hydrolysis was found to be unknown impurity. The stress samples were assayed against a qualified reference standard and the mass balance was found close to $99.5 \%$. The developed RP-UPLC method was validated with respect to linearity, accuracy, precision and robustness. The developed method was found to be linear in the range of 30$150 \mu \mathrm{g} / \mathrm{mL}$ with correlation coefficient of 0.999 for assay procedures and found to be linear in the range of $0.1-3 \mu \mathrm{g} / \mathrm{mL}$ with correlation coefficient of 0.999 for related impurities.
\end{abstract}

Key Words: RP-UPLC, Forced degradation, Validation, Rufinamide, Method development.

\section{INTRODUCTION}

Rufinamide is an antiepileptic drug approved by the US Food and Drug Administration as adjunctive treatment of seizures associated with Lennox-Gastaut syndrome in children 4 years and older and adults. Lennox-Gastaut syndrome consists of avariety of treatment-resistant seizures and is most common among paediatric patients ${ }^{1}$. Rufinamide is chemically known as 1- [(2, 6-difluorophenyl) methyl]-1H-1,2,3-triazole4-carboxamide with molecular formula $\mathrm{C}_{10} \mathrm{H}_{8} \mathrm{~N}_{4} \mathrm{OF}_{2}$ and molecular weight $238.19 \mathrm{~g} / \mathrm{mol}$ as shown in Fig. 1. The mechanism of action of rufinamide is unknown but it is presumed to involve stabilization of the sodium channel inactive state, effectively keeping the ion channels closed. It is believed to prolong the refractory period of voltage dependent sodium channels, making neurons less likely to fire ${ }^{2}$. Very few methods are reported in the literature regarding the clinical studies and no stability indicating method is available in the official compendia using HPLC for analysing rufinamide in dosage forms. Analytical methods for rufinamide from pharmaceutical dosage form should be developed and validated. To date, all analytical methods described in literature for the determi-

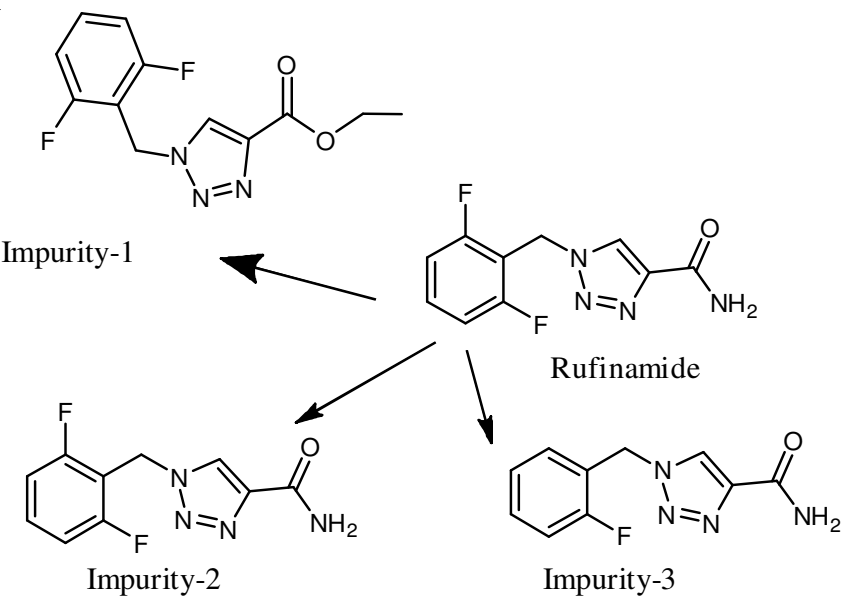

Fig. 1. Chemical structures, of rufinamide and its related impurities

nation of rufinamide in biological fluids involve liquid chromatography $^{3.7}$ and liquid chromatography ${ }^{8,9}$ and LC-MS methods ${ }^{10}$.

A limited number of analytical techniques have been reported for the quantitative determination of rufinamide in 
pharmaceutical preparations and human plasma when present alone or in combination with other drugs (rufinamide, zonisamide, lamotrigine, oxcarbazepine monohydroxy derivative and felbamate in deproteinized plasma). These techniques HPLC12, Enzyme-linked immune sorbent assay ${ }^{6}$, HPLC. In order to commercialize an active pharmaceutical ingredient, it is mandatory requirement from regulatory authorities to show the proper qualification of its impurities identification and characterization of known impurities that are present. Organic impurities can arise during the manufacturing process and storage of the drug substances and their acceptance upto certain limits are based on pharmaceutical studies or known safety data. In the present study we describe a simple, economic and time efficient reversed phase liquid chromatography (RPUPLC) method for the separation and quantification of process related impurities of rufinamide. The accuracy, precision, limit of detection (LOD), limit of quantification (LOQ) and Linearity of the method was determined in accordance with ICH guidelines ${ }^{11,12}$ and found to be suitable for quality assurance of rufinamide. The paper provides the validated stability indicated RP-UPLC method which separates potential impurities for first time. To the best of our knowledge, there was no method application by UPLC presented for the related impurities. Here we are presenting first time the use of UPLC method for quantification of Rufinamide and its impurities with a run time of $17 \mathrm{~min}$ by separating the related four impurities with a resolution more than 2. The limit of quantification of impurity-1, impurity-2 and impurity- 3 were $0.051,0.045$ and $0.040 \%$ (of analyte concentration, i.e., $0.5 \mathrm{mg} / \mathrm{mL}$ ) with $2 \mu \mathrm{L}$ injection volume.

\section{EXPERIMENTAL}

Samples of rufinamide and its related impurities were obtained as gift samples from drreddys (Hyderabad, India) (Figs. 1 and 2). HPLC grade methanol, analytical reagent grade potassium dihydrogen orthophosphate were purchased from Merck, Darmstadt, Germany. High purity water was prepared by using Millipore Milli-Q plus water purification system. All samples and impurities used in this study were of greater than $95 \%$ purity.

The UPLC system, used for method development, forced degradation studies and method validation was waters ACQUITY TM UPLC system equipped with a diode array detector, Waters Corp. (Milford, MA, USA). The output signal was monitored and processes using Empower software (Waters) Water bath equipped with temperature controller was used to carry out degradation studies for all solution.

Chromatographic conditions: The chromatographic column used was a waters ACQUITY TM UPLC BEH $\mathrm{C}_{18}$ column $150 \mathrm{~mm} \times 2.1 \mathrm{~mm}, 1.7 \mu \mathrm{m}$, all obtained from Waters Corp. (Milford, MA, USA). The isocratic LC method consists buffer, methanol and tetrahydrofuran in the ratio of $(80: 15: 5$ $\mathrm{v} / \mathrm{v}$ ) as mobile phase. The buffer solution contains $0.02 \mathrm{M}$ potassium dihydrogen orthophosphate $\mathrm{pH}$ adjusted to 4.5 with ortho phosphoric acid. The flow rate of the mobile phase was $0.3 \mathrm{~mL} / \mathrm{min}$. The column temperature was maintained $40{ }^{\circ} \mathrm{C}$ and the detection was monitored at a wavelength of $210 \mathrm{~nm}$. The injection volume was $2 \mu \mathrm{L}$. Mixture water: methanol (1:1) was used as a diluent. The concentration is $0.5 \mathrm{mg} \mathrm{mL}^{-1}$ for related impurities method and $0.007 \mathrm{mg} \mathrm{mL}^{-1}$ for assay method.
Preparation of solutions: A stock solution of rufinamide $\left(0.5 \mathrm{mg} \mathrm{mL}^{-1}\right)$ was prepared by dissolving appropriate amount in the diluent. Working solutions were prepared from above stock solution for related impurities determination and assay determination, respectively. A stock solution of impurities (mixture of impurity-1, impurity-2 and impurity-3) at a concentration of $0.5 \mathrm{mg} \mathrm{mL}^{-1}$ was also prepared in diluent.

Specificity: Specificity is the ability of the method to measure the analyte response in the presence of its potential impurities. Stress testing of the drug impurities can help identify the likely degradation products, which can in turn help establish the degradation pathways and the intrinsic stability of the molecule and validate the stability indicating power of the analytical procedures used.

The specificity of the developed LC method for rufinamide was determined in the presence of its impurities, namely impurity-1, impurity-2 and impurity-3 and degradation products. Forced degradation studies were also performed on rufinamide to provide an indication of the stability indicating property and specificity of the proposed method. The stress conditions employed for degradation study includes, acid hydrolysis $(0.1$ $\mathrm{N} \mathrm{HCl}$ ), base hydrolysis $(0.1 \mathrm{~N} \mathrm{NaOH}$ for $2 \mathrm{~h}$. Peak purity of stressed samples of rufinamide was checked by using photo diode array detector (PDA). The purity factor is within the threshold limit obtained in all stressed samples demonstrates the analyte peak homogeneity. Assay studies were carried out for stress samples against qualified reference standard and the mass balance (assay $\%+$ impurities $\%+$ degradation $\%$ products) was calculated. Specificity of the rufinamide was shown by spiking all three impurities (impurity-1, impurity-2 and impurity-3 (i.e. $0.15 \%$ of analyte concentration which is $0.5 \mathrm{mg} / \mathrm{mL}$ ).

Analytical method validation: The developed chromatographic method was validated for linearity, precision, accuracy, sensitivity, robustness and system suitability.

Precision: The precision of the related impurities method was checked by injecting six individual preparations of $(0.5$ $\mathrm{mg} \mathrm{mL}^{-1}$ ) rufinamide spiked with $0.15 \%$ each impurity-1, impurity-2 and impurity-3. The \%RSD area of each impurity1, impurity-2 and impurity-3 was calculated. Assay method precision was evaluated by carrying out six independent assays of test sample of rufinamide against qualified reference standard. The percentage of RSD of six assay values obtained was calculated (Table-1).

TABLE-1

INTRA-DAY PRECISION AND INTER DAY PRECISION

\begin{tabular}{ccc}
\hline S. No. & Assay $(\%)$ & Assay $(\%)$ \\
\hline 1 & 102.7 & 101.5 \\
2 & 102.0 & 100.8 \\
3 & 102.3 & 101.2 \\
4 & 102.9 & 100.6 \\
5 & 102.3 & 100.9 \\
6 & 102.0 & 101.6 \\
Average assay (\%) & 102.4 & 101.1 \\
RSD $(\%)$ & 0.4 & 0.4 \\
\hline
\end{tabular}

Limit of detection (LOD) and limit of quantification (LOQ): Sensitivity was determined by establishing the limit of detection (LOD) and limit of quantitation (LOQ) for impurity-1, impurity-2 and impurity-3 estimated at a signal-to-noise 
ratio of 3:1 and 10:1, respectively, by injecting a series of dilute solutions with known concentration. The precision study was also carried out at the LOQ level by injecting six individual preparations impurity-1, impurity-2 and impurity-3, calculated the $\%$ RSD for the areas of each impurity (Table-2).

\begin{tabular}{ccc}
\multicolumn{3}{c}{ TABLE-2 } \\
& LOD AND LOQ VALUES \\
\hline Name of the & \multicolumn{2}{c}{ Impurity (\%) } \\
\cline { 2 - 3 } impurity & Limit of quantification & Limit of detection \\
\hline Impurity-1 & 0.051 & 0.019 \\
Impurity-2 & 0.045 & 0.018 \\
Impurity-3 & 0.040 & 0.015 \\
Rufinamide & 0.030 & 0.010 \\
\hline
\end{tabular}

Linearity and range: A linearity test solution for related impurities method was prepared by diluting the impurity stock solution to the required concentrations. The solutions were prepared at six concentration levels. From 0.05 to $0.3 \%$ of the permitted maximum level of the impurity (i.e., 0.05, 0.1, $0.15,0.2,0.25$ and $0.3 \%$ was subjected to linear regression analysis with the least square method. Calibration equation obtained from regression analysis was used to calculate the corresponding predicted responses. The residuals and sum of the residual squares were calculated from the corresponding predicted responses.

Linearity test solutions for assay method has prepared from stock solution at five concentration levels from 25 to $150 \%$ of assay analyte concentration.

\section{RESULTS AND DISCUSSION}

Development method and optimization: The main target of the chromatographic method is to get the separation of critical closely eluting peaks, namely rufinamide, impurity- 2 and impurity-3. Impurities were co-eluted by using different stationary phases like $\mathrm{C}_{18}$, phenyl and cyano and different mobile phases containing buffers like phosphate, sulphate and acetate with different $\mathrm{pH}(2-8)$ and using organic modifiers like acetonitrile, methanol and ethanol in the mobile phase. The chromatographic separation was achieved on a Waters ACQUITY TM UPLC BEH $\mathrm{C}_{18}$ column $150 \mathrm{~mm} \times 2.1 \mathrm{~mm}$, $1.7 \mu \mathrm{m}$ column, the isocratic LC method consists buffer, methanol and tetrahydrofuran in the ratio of $(80: 15: 5 \mathrm{v} / \mathrm{v})$ as mobile phase. The buffer solution contains $0.02 \mathrm{M}$ potassium dihydrogen orthophosphate $\mathrm{pH}$ adjusted to 4.5 with orthophosphoric acid. The flow rate of the mobile phase was $0.3 \mathrm{~mL} /$ min. The column temperature was maintained $40{ }^{\circ} \mathrm{C}$ and the detection was monitored at a wavelength of $210 \mathrm{~nm}$. The injection volume was $2 \mu \mathrm{L}$. Mixture water: methanol (1:1) was used as a diluent. The concentration is $0.5 \mathrm{mg} \mathrm{mL}^{-1}$ for related impurities method and $0.007 \mathrm{mg} \mathrm{mL}^{-1}$ for assay method. The peak shape of rufinamide was found symmetrical. In the optimized conditions rufinamide, impurity-1, impurity- 2 and impurity-3 were well separated with a resolution of greater than 2 and the typical retention times of rufinamide, impurity3, impurity-2 and impurity-1 were 4.16, 4.68, 5.74 and 15.39 min, respectively. The system suitability results are given in Table-1 and the developed UPLC method was found to be specific for rufinamide and its three impurities, namely impu- rity-1, impurity-2 and impurity-3. After many logical trials, chromatographic condition was established such that which could be suitable for separation of drug-degradation products and drug-three known impurities. Using the optimized conditions rufinamide and its known impurities were well separated with a resolution of greater than 2 (Fig. 2). The system suitability results are given in Table- 3 .

\begin{tabular}{lcc}
\multicolumn{3}{c}{ TABLE-3 } \\
SYSTEM SUITABILITY \\
\hline \multicolumn{1}{c}{ System suitability parameters } & $\begin{array}{c}\text { Observed } \\
\text { value }\end{array}$ & $\begin{array}{c}\text { Acceptance } \\
\text { citeria }\end{array}$ \\
\hline $\begin{array}{l}\text { Tailing factor for rufinamide peak from } \\
\text { standard preparation }\end{array}$ & 0.9 & NMT 2.0 \\
$\begin{array}{l}\text { Relative standard deviation for rufinamide } \\
\text { peak area for five replicate injections of } \\
\text { standard preparation }\end{array}$ & 0.9 & $\begin{array}{c}\text { NMT 2.0 } \\
\%\end{array}$ \\
$\begin{array}{l}\text { USP plate count for the rufinamide peak } \\
\text { from standard chromatogram }\end{array}$ & 3693 & NLT 2000 \\
\hline
\end{tabular}

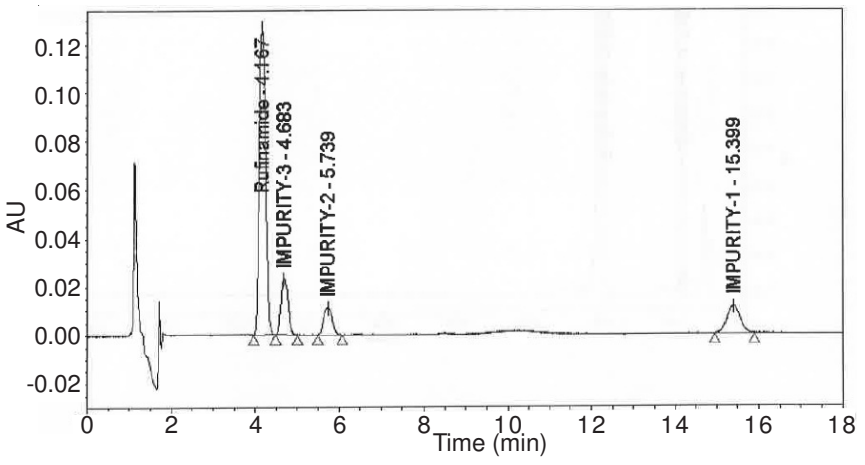

Fig. 2. Chromatogram of impurity spiked solution

Results of forced degradation studies: The drug was exposed to $0.1 \mathrm{~N} \mathrm{HCl}$ at $70{ }^{\circ} \mathrm{C}$ for $24 \mathrm{~h}$. Rufinamide has shown significant sensitivity towards the treatment of $0.1 \mathrm{~N} \mathrm{HCl}$. The drug gradually undergone degradation with time in $0.1 \mathrm{~N} \mathrm{HCl}$ and prominent degradation was observed $(15 \%)$. The representative chromatogram presented in Fig. 3.

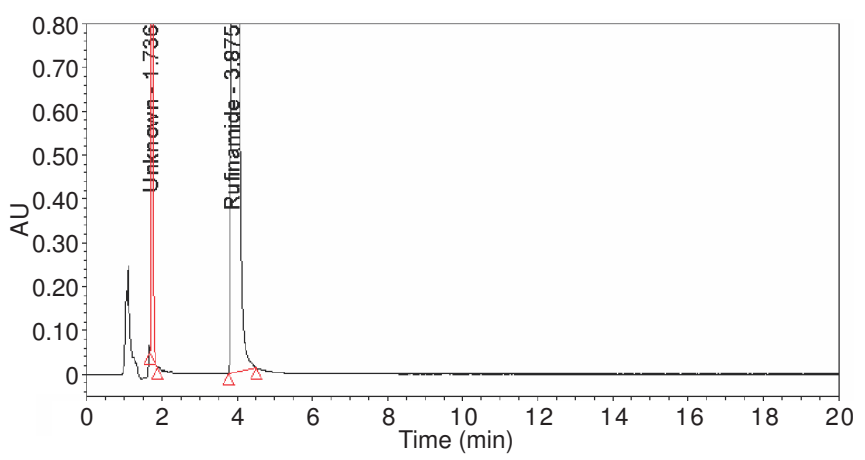

Fig. 3. Typical chromatogram of acid degradation

Degradation in basic solution: The drug was exposed to $0.1 \mathrm{~N} \mathrm{NaOH}$ at $70^{\circ} \mathrm{C}$ for $24 \mathrm{~h}$. Rufinamide has shown mild sensitivity towards the treatment of $0.1 \mathrm{~N} \mathrm{NaOH}$. The drug gradually undergone degradation with time in $0.1 \mathrm{~N} \mathrm{NaOH}$ and degradation was observed $(2 \%)$. The chromatogram presented in Fig. 4.

Robustness: Close observation of analysis results for deliberately changed chromatographic conditions (flow rate, $\mathrm{pH}$ and column temperature) revealed that the resolution 


\begin{tabular}{|c|c|c|c|c|c|}
\hline \multicolumn{6}{|c|}{$\begin{array}{c}\text { TABLE-5 } \\
\text { ROBUSTNESS }\end{array}$} \\
\hline Parameter & $\begin{array}{l}\text { Flow } 0.28 \\
\mathrm{~mL} / \mathrm{min}\end{array}$ & $\begin{array}{l}\text { Flow } 0.32 \\
\mathrm{~mL} / \mathrm{min}\end{array}$ & $\begin{array}{l}\text { Column temp. } \\
\quad 38^{\circ} \mathrm{C}\end{array}$ & $\begin{array}{l}\text { Column } \\
\text { temp. } 42{ }^{\circ} \mathrm{C}\end{array}$ & $\begin{array}{l}\text { Acceptance } \\
\text { criteria }\end{array}$ \\
\hline $\begin{array}{l}\text { Tailing factor for rufinamide peak from standard } \\
\text { preparation }\end{array}$ & 0.9 & 0.9 & 0.9 & 1.0 & NMT 2.0 \\
\hline $\begin{array}{l}\text { Relative standard deviation for rufinamide peak area for } \\
\text { five replicate injections of standard preparation }\end{array}$ & 0.8 & 1.1 & 1.6 & 1.2 & NMT $2.0 \%$ \\
\hline $\begin{array}{l}\text { USP plate count for the rufinamide peak from standard } \\
\text { chromatogram }\end{array}$ & 3800 & 3600 & 3852 & 3320 & NLT 2000 \\
\hline
\end{tabular}

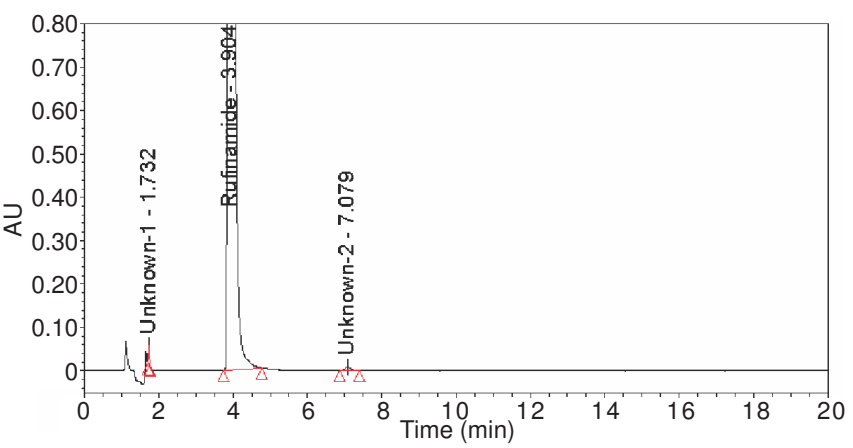

Fig. 4. Typical chromatogram of base degradation

between closely eluting peaks, namely rufinamide and impurity-3 was always greater than 2 , illustrating the robustness of the method.

Solution stability and mobile phase stability: No significant changes were observed in the content impurity-1, impurity-2 and impurity-3 during solution stability and mobile phase stability experiments for related impurities. The \% RSD of assay of rufinamide during solution stability and mobile phase stability experiments was within \pm 1 . The solution stability and mobile phase stability experiments data confirms that sample solutions and mobile phase used during assay and related impurities determination were stable up to the study period of $48 \mathrm{~h}$.

Assay analysis: Analysis was performed for different batches of rufinamide in bulk drug samples $(n=3)$ ranged from 100.8-102.9\% (Table-4).

\begin{tabular}{cccccc}
\multicolumn{7}{c}{ TABLE-4 } \\
\hline \multicolumn{7}{c}{ RECOVERY FOR THE RUFINAMIDE IN ASSAY } \\
\hline Sr. & $\begin{array}{c}\text { Spike } \\
\text { level }\end{array}$ & $\begin{array}{c}\text { Added } \\
(\mathrm{mg})\end{array}$ & $\begin{array}{c}\text { Found } \\
(\mathrm{mg})\end{array}$ & $\begin{array}{c}\text { Recovery } \\
(\%)\end{array}$ & $\begin{array}{c}\text { Mean recovery } \\
(\%)\end{array}$ \\
\hline 1 & & 3.61 & 3.58 & 99.5 & \\
2 & 50 & 3.58 & 3.54 & 100.3 & 98.7 \\
3 & & 3.56 & 3.49 & 99.8 & \\
\hline 1 & & 7.21 & 7.19 & 99.2 & \\
2 & \multirow{2}{*}{100} & 7.12 & 7.08 & 98.9 & 99.4 \\
3 & & 7.18 & 7.12 & 98.0 & \\
\hline 1 & & 10.54 & 10.51 & 99.7 & \\
2 & 150 & 10.58 & 10.48 & 99.1 & 99.3 \\
3 & & 10.65 & 10.56 & 99.2 & \\
\hline
\end{tabular}

Dissolution analysis: The peak in $\mathrm{pH} 6.8$ phosphate buffer with sodium lauryl sulphate is also good. So we can adopt this method for dissolution also with a run time of $6 \mathrm{~min}$.

\section{Conclusion}

The RP-UPLC method developed for both assay and related impurities was linear, precise, accurate and specific. The method was completely validated showing satisfactory data for all the method validation parameters tested for both assay and related impurities as per ICH guidelines. The developed method is stability indicating and can be used for the routine analysis of production samples and also to check the stability of rufinamide samples same procedures on a different day (interday precision).

\section{ACKNOWLEDGEMENTS}

The authors thank the management of Dr. Reddy's Laboratories Ltd. for supporting this work. Cooperation from the colleagues of Research \& Development and Analytical Research \& Development of Dr. Reddy's Laboratories Ltd. is appreciated.

\section{REFERENCES}

1. The Merck Index, an Encyclopedia of Chemicals Drug and Biologicals, Published by Merck Research Laboratories, Division of Merck and Co. Inc., Whitehouse Station, NJ, edn. 14, p. 505 (2006).

2. M.J. McLean, M. Schmutz, M.F. Pozza and A. Wamil, Epilepsia, 46S, 375 (2005).

3. L.A. Brunner and M.L. Powell, Biomed. Chromatogr., 6, 278 (1992).

4. M.C. Rouan, C. Souppart, L. Alif, D. Moes, J.B. Lecaillon and J. Godbillon, J. Chromatogr. B; Biomed. Appl., 667, 307 (1995).

5. M.C. Rouan, C. Buffet, L. Masson, F. Marfil, H. Humbert and G. Maurer, J. Chromatogr. B; Biomed. Sci. Appl., 754, 45 (2001).

6. M. Contin, S. Mohamed, C. Candela, F. Albani, R. Riva and A. Baruzzi, J. Chromatogr. B; Anal. Technol. Biomed. Life Sci., 878, 461 (2010).

7. I. Mazzucchelli, M. Rapetti, C. Fattore, V. Franco, G. Gatti and E. Perucca, Anal. Bioanal. Chem., 401, 1013 (2011).

8. S. Muneer, C.J.G. Babu, R. Hakeem and K.S. Sumanth, Int. J. Pharm. Res. Anal., 2, 9 (2012).

9. M.M. Annapurna, B.S.P. Kumar, S.V.S. Goutam and L. Srinivas, J. Drug Deliv. Therap., 2, 167 (2012).

10. G. la Marca, S. Malvagia, L. Filippi, M. Innocenti, A. Rosati, M. Falchi, S. Pellacani, G. Moneti and R. Guerrini, J. Pharm. Biomed. Anal., 54, 192 (2011).

11. ICH Validation of Analytical Procedures: Text and Methodology Q2 (R1), International Conference on Harmonization (2005).

12. ICH Stability Testing of New Drug Substances and Products Q1A (R2), International Conference on Harmonization (2003). 